\title{
Synthesis and characterization of thiourea
}

\author{
Chuanbo Dai ${ }^{3^{*}}$, Hongyu Zhang ${ }^{1,2,3}$, Ruiduan $\mathrm{Li}^{\mathbf{2}^{*}}$, Haifeng Zou ${ }^{{ }^{*}}$ \\ ${ }^{1}$ Jilin University, College of Chemistry, Changchun 130021, China \\ ${ }^{2}$ Jilin Institute of Chemical Technology, Jilin 132022, China \\ ${ }^{3}$ Jiaying College, Meizhou 514021, China \\ Corresponding author: e-mail: daichb@163.com
}

\begin{abstract}
Herein, a simple and effective method for the preparation of thiourea using a nucleophilic substitution reaction is reported. Urea and Lawesson's reagent were used as the raw materials to prepare thiourea via a one-step method involving the sulfuration reaction, and the reaction mechanism was analyzed. The effect of the reaction time, reaction temperature, and mass ratio of the raw materials on the yield of thiourea were investigated.The most beneficial conditions used for the reaction were determined to be: Reaction time $=3.5 \mathrm{~h}$, reaction temperature $=75^{\circ} \mathrm{C}$, and mass ratio of urea to Lawesson's reagent $=2: 1$. Under these optimal conditions, the average yield of thiourea over five replicate experiments was $62.37 \%$. Characterization using Fourier transform infrared (FTIR) spectroscopy, X-ray diffraction (XRD) and thermogravimetric analysis (TGA) showed that the as-synthesized substance was thiourea. Our synthetic method has the advantages of high yield, mild reaction conditions and simplicity.
\end{abstract}

Keywords: Urea, Lawesson's reagent, thiourea, vulcanization reaction, Nucleophilic substitution.

\section{INTRODUCTION}

Thiourea (CAS No. 62-56-6) has the molecular formula, $\mathrm{CSN}_{2} \mathrm{H}_{4}$. It can be isolated as colorless to pale yellow orthorhombic or needle-like glossy crystals with a bitter taste and ammonia-like odor. Thiourea is slightly soluble in cold water, soluble in hot water, and can be recrystallized from ethanol Thiourea is a general reagent used in synthetic chemistry and belongs to the thioamide family of compound. Thiourea has an increasingly important use in chemical ${ }^{1,2}$,medicine ${ }^{3}$, agriculture ${ }^{4}$ and adsorbent industry $^{5,6}$, but little research has been done on synthesizing at home and abroad. The literature on synthesis is outdated and its production technology is backward. Furthermore,there's nothing about one-step synthesis reports. Therefore, it is necessary to have an indepth study of synthesizing.

The previously reported syntheses of thiourea include methods using urea-calcium cyanamide, urea-cyanamide, cyanamide, carbon disulfide and ammonium thiocyanate isomerization, lime nitrogen, and cyanamide-hydrogen sulfide. The urea- calcium cyanamide method $^{7}$ uses calcium cyanamide $\left(\mathrm{CaCN}_{2}\right)$ and calcium oxide as the raw materials to form an intermediate product, $\mathrm{Ca}(\mathrm{OCN})_{2}$, which reacts with $\mathrm{H}_{2} \mathrm{~S}$ to form thiourea.However, this method has a high production cost and small profit margin. In addition, the viscous $\mathrm{Ca}(\mathrm{OCN})_{2}$ intermediate produced during the process cannot be removed from the reaction system for the subsequent reaction in the thiourea synthesis because there is no supporting equipment.Calcium hydroxide, the by-product produced in the reaction with hydrogen sulfide, has a low solubility in water, and eventually forms a thick agglomerate in the reaction vessel,which seriously affects the progress of the reaction. The urea-cyanamide method ${ }^{8}$ involves the dehydration of urea under normal pressure to form cyanamide $\left(\mathrm{H}_{2} \mathrm{CN}_{2}\right)$, which is then reacted with hydrogen sulfide to form thiourea $\mathrm{A}$ large number of side reactions occur during the process, and the yield of the target product is usually low $(\sim 32 \%)$. The cyanamide method ${ }^{9}$ involves the reaction of ammonia with carbon dioxide to form $\mathrm{H}_{2} \mathrm{CN}_{2}$, which is then reacted with $\mathrm{H}_{2} \mathrm{~S}$ to form thiourea. The reaction is difficult to perform due to the inertness of carbon dioxide, and the reaction yield is usually low $(\sim 30 \%)$ which results in high production costs. The carbon disulfide method ${ }^{10}$ involves the use of carbon disulfide and ammonia as the raw materials to prepare, dithiocarbamate, which is then decomposed into ammonium thiocyanate. The ammonium thiocyanate formed is then isomerized to form thiourea, producing hydrogen sulfide as a by-product. The highest yield reported for this process is $11.5 \%$, and the low yield is mainly attributed to the isomerization of ammonium thiocyanate and the physical and chemical properties of the ammonium thiocyanate intermediate and thiourea product. In addition, there is currently no effective separation method used in this synthesis, which is also a bottleneck in the process. The ammonium thiocyanate isomerization method ${ }^{\mathbf{1 1}}$ uses ammonium thiocyanate as the raw material to obtain thiourea. The yield reported for this method does not exceed $30 \%$, which results in high production costs. The lime nitrogen method ${ }^{12}$ produces lime milk upon reacting calcium oxide with water, which absorbs hydrogen sulfide to obtain calcium hydrosulfide. The thiourea is further prepared by mixing Lime nitrogen and The calcium hydrosulfide. The yield of thiourea reported using this method is only $60 \%$. The synthesis of thiourea via the cyanamide-hydrogen sulfide method ${ }^{13}$ uses cyanamide which can be prepared using two processes: Lime nitrogen synthesis and urea atmospheric pressure dehydration. The lime nitrogen synthesis uses sulfuric acid as a weak acid catalyst to decompose lime nitrogen into cyanamide at low temperature. A modified atmospheric molecular sieve is used as the catalyst to in the urea atmospheric pressure dehydration step, which is performed under an ammonia atmosphere, to form cyanamide. Thiourea is then prepared in a concentrated aqueous ammonia solution of cyanamide and hydrogen sulfide gas. The total yield of thiourea using this method can reach 33\%. In this study, urea and Lawesson's reagent were used as the raw materials to prepare thiourea via a one-step method through sulfuration reaction. The most beneficial conditions were investigated and the resulting product was characterized. Our study aims to establish 
a high yielding, mild and simple preparation method for the synthesis of thiourea.

\section{EXPERIMENTAL}

Lawesson's reagent (80\% purity), urea, and tetrahydrofuran (analytical grade) obtained from Kang Baotai Fine Chemical Co., Ltd. Ultrapure water was used throughout our study. Fourier transform infrared (FT-IR) spectra were recorded using $\mathrm{KBr}$ discs on a Shimadzu $8400 \mathrm{~S}$ spectrophotometer. The absorbance spectra were recorded on a UV $9100 \mathrm{D}$ UV-Vis spectrophotometer manufactured by Beijing Laibo Tyco Instrument Co., Ltd. Thermogravimetric analysis (TGA) was carried out under a nitrogen atmosphere on a Shimadzu TGA-50 thermal analyzer. The crystal structure of the thiourea product was characterized using X-ray powder diffraction (XRD) recorded on a Bruker-D8 Advance diffractometer using $\mathrm{Cu} \mathrm{K} \alpha$ radiation.

\section{Synthesis of thiourea}

The synthesis of thiourea is shown in Fig. 1.

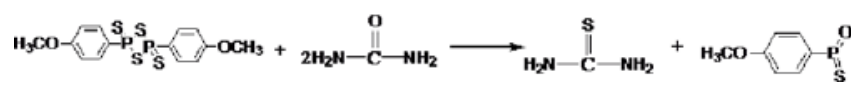

Figure 1. Synthesis of thiourea using Lawesson's reagent and urea

Lawesson's reagent $(2 \mathrm{~g}, 0.005 \mathrm{~mol})$ and urea $(1 \mathrm{~g}$, $0.017 \mathrm{~mol}$ ) were added to $40 \mathrm{~mL}$ of tetrahydrofuran and the resulting solution heated in a water bath at $343 \mathrm{~K}$ for $4 \mathrm{~h}$ under an atmosphere of $\mathrm{N}_{2}$. The reaction mixture was cooled to room temperature and the tetrahydrofuran removed via distillation. and the Lawesson's reagent and urea were dissolved in tetrahydrofuran by stirring to form a yellow transparent mixed solution. The reaction slowly and a white substance was formed at the bottom of the bottle of the three-mirror flask. The white material is thiourea and by-product thiophosphorus ylide, as well as excess urea. After the reaction is completed, the product is purified by a method of dissolving and filtering, using n-butanol as a solvent, and then by-products in the experiment are rec-overed.

\section{Determination of the product composition}

The reaction mechanism for the preparation of thiourea using urea and Lawesson's reagent is shown in Figure 2. Lawesson's reagent is decomposed into two molecules upon heating. Urea is a typical amide structure and contains a carbonyl group in which the $\mathrm{C}$ atom carries a partial positive charge and the $\mathrm{O}$ atom a partial negative charge, and a nucleophilic reaction occurs. The sulfur anion of Lawesson's reagent attacks the carbon of urea. The positive ions, the phosphorus cations of Lawesson's reagent and the oxygen anions of urea form a $\mathrm{C}, \mathrm{O}, \mathrm{P}, \mathrm{S}$ four-membered ring transition state. The quaternary transition ring is unstable, and the electrons of the phosphorus-sulfur bond migrate to the phosphorus-oxygen bond to form a thiophosphorus ylide. At the same time, the carbon-oxygen single bond is broken, and the carbon-sulfur bond transforms to a double bond, forming thiourea.

The absorption spectrum of a standard sample of thiourea was recorded using ultraviolet-visible absorption

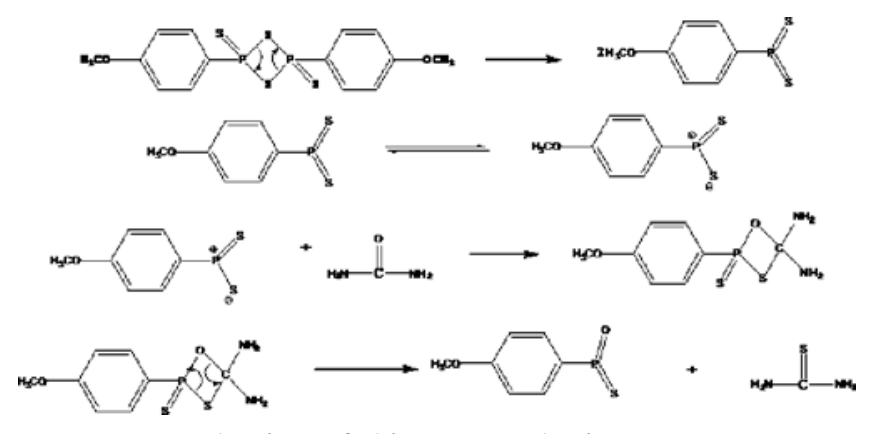

Figure 2. Mechanism of thiourea synthesis

spectroscopy in the range of $200-1000 \mathrm{~nm}$, as shown in Fig. 3. The maximum absorbance was observed at $235 \mathrm{~nm}$.

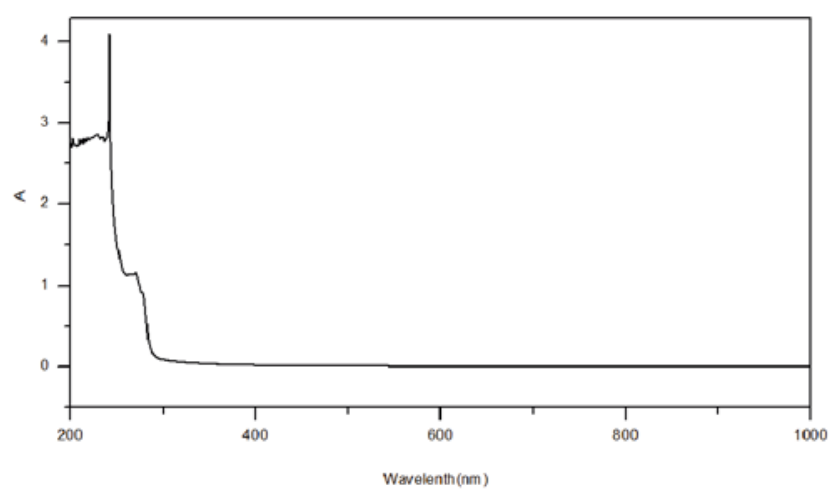

Figure 3. The absorption spectrum of thiourea

To obtain the value of the yield, the yield of thiourea can be conveniently calculated using the standard curve of thiourea. The pure sample of $0.01 \mathrm{~g}$ of thiourea into $100 \mathrm{ml}$ of solution, and several parts were diluted. The absorbance value was measured at $235 \mathrm{~nm}$, and the standard curve of absorbance versus concentration was plotted. 4 is shown. For sample analysis, the absorbance (A) of the crude sample was measured at $235 \mathrm{~nm}$ and used to calculate the thiourea content (C). This assay has the advantages of simplicity, sensitivity, rapidity, high selectivity, and good stability.

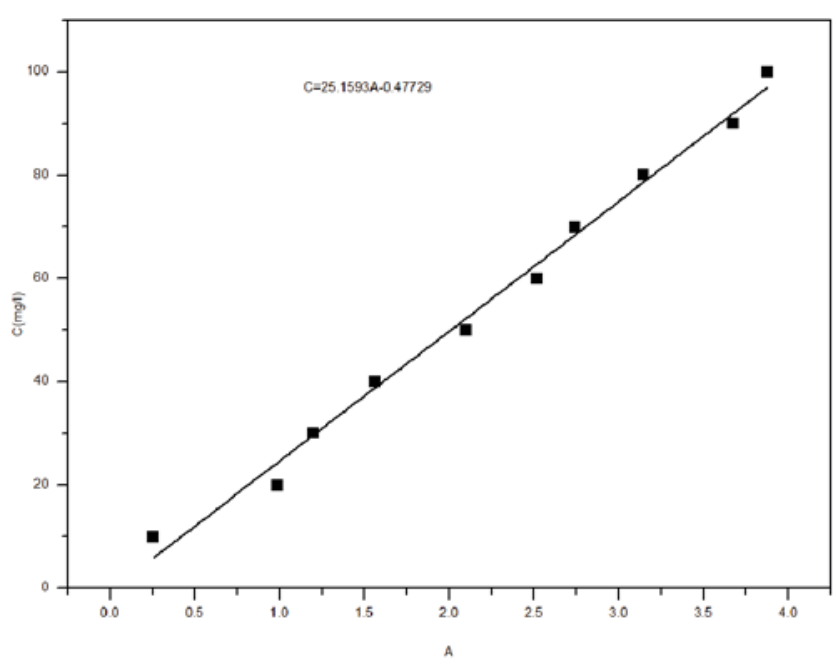

Figure 4. Standard curve of absorption and concentration obtained for thiourea 


\section{RESULTS AND DISCUSSION}

Effect of the mass ratio of reactants on the yield of thiourea

We explored the effect of different mass ratios of Lawesson's reagent and urea on the reaction yield. Due to the large molar mass of Lawesson's reagent and to reduce waste, the other reactions conditions were kept unchanged. The reaction was performed using $40 \mathrm{~mL}$ of tetrahydrofuran and heated in a water bath at $343 \mathrm{~K}$ for $4 \mathrm{~h}$ under an atmosphere of $\mathrm{N}_{2}$ using various mass ratios of Lawesson's reagent and urea (3.2:1, 2.7:1, 2.3:1, 2:1, and 1:1). The experimental results are shown in Fig. 5.

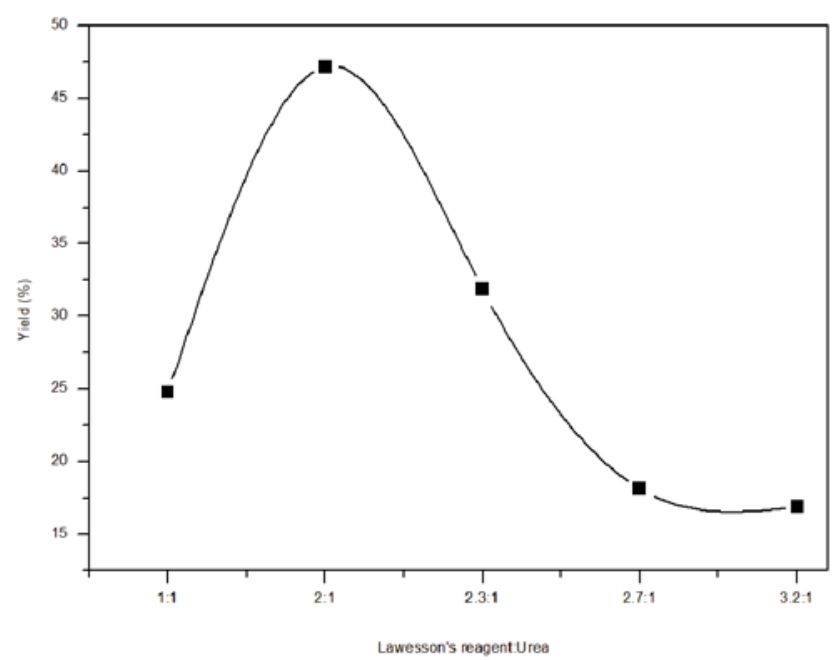

Figure 5. Effect of the mass ratio of Lawesson's reagent and urea on the yield of thiourea

Upon increasing the mass ratio of Lawesson's reagent and urea to $2: 1$, the yield of thiourea rapidly increased to $47.18 \%$. However, when the mass ratio was further increased, the amount of Lawesson's reagent and steric hindrance effect increases and the molecular collision rate between Lawesson's reagent and urea decreases, which affects the reaction, and results in a decrease in the reaction yield. Therefore, the most beneficial ratio of Lawesson's reagent and urea was found to be 2:1.

Effect of the reaction temperature on the yield of thiourea

Under the condition that the mass ratio of Lawesson's reagent to urea is $2: 1$, other reaction conditions are kept unchanged Lawesson's reagent (2.0035 g, 0.005 $\mathrm{mol})$, urea $(1.0869 \mathrm{~g}, 0.018 \mathrm{~mol})$, was added to $40 \mathrm{ml}$ of tetrahydrofuran and heated for $4 \mathrm{~h}$ in a N2 atmosphere, and the temperature of the water bath was changed to investigate the change in the yield, as shown in Fig. 6.

Initially, a gradual increase in the reaction temperature increases the number of reactant molecules that exceed the activation energy of the reaction, which increases both the reaction conversion rate and yield. The reaction yield reaches its maximum $(64.14 \%)$ at $348 \mathrm{~K}$. As the reaction temperature is further increased, the selectivity of the reaction decreases, the number of side reactions increase, and the product decomposes due to high temperature, all of which cause a decrease in the reaction yield. Therefore, the most beneficial reaction temperature was found to be $348 \mathrm{~K}$.

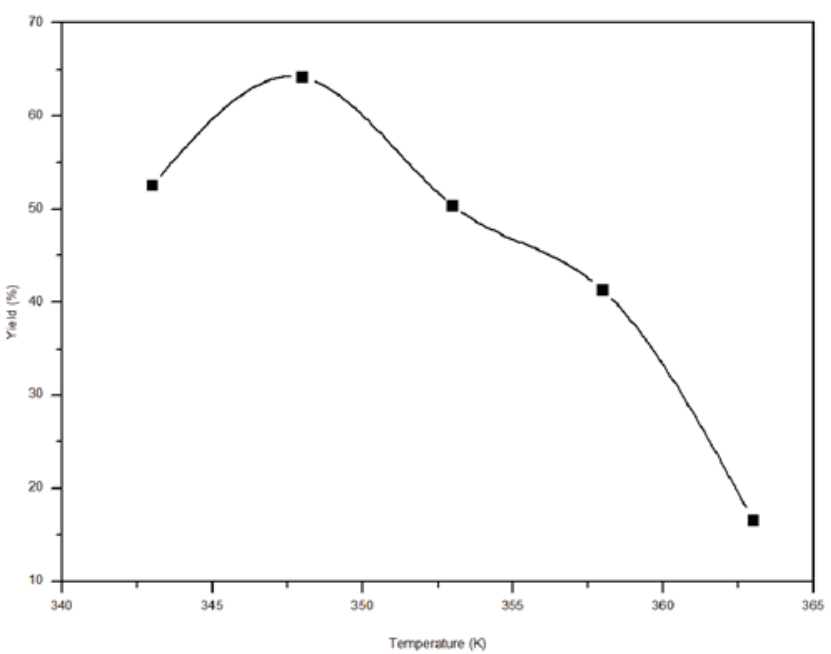

Figure 6. Effect of the reaction temperature on the yield of thiourea

\section{Effect of the reaction time on the yield of thiourea}

We explored the effect of the reaction time on the yield of thiourea. Lawesson's reagent $(2.0 \mathrm{~g}, 0.005 \mathrm{~mol})$ and urea $(1.0 \mathrm{~g}, 0.017 \mathrm{~mol})$ were reacted using the most beneficial mass ratio of $2: 1$ and reaction temperature of $348 \mathrm{~K}$ in $40 \mathrm{~mL}$ of tetrahydrofuran and magnetically stirred under a nitrogen atmosphere for various reaction times $(3,3.5,4,4.5$, and $5 \mathrm{~h}$, respectively). The experimental results are shown in Fig. 7 . When the reaction time is less than $3.5 \mathrm{~h}$, the reaction is still in progress. Therefore, the yield of thiourea is low, reaching a maximum value of $69.23 \%$ after 3.5 h. However, a further increase in the reaction time leads to product decomposition and the reaction yield decreases. Therefore, the most beneficial reaction time was found to be $3.5 \mathrm{~h}$.

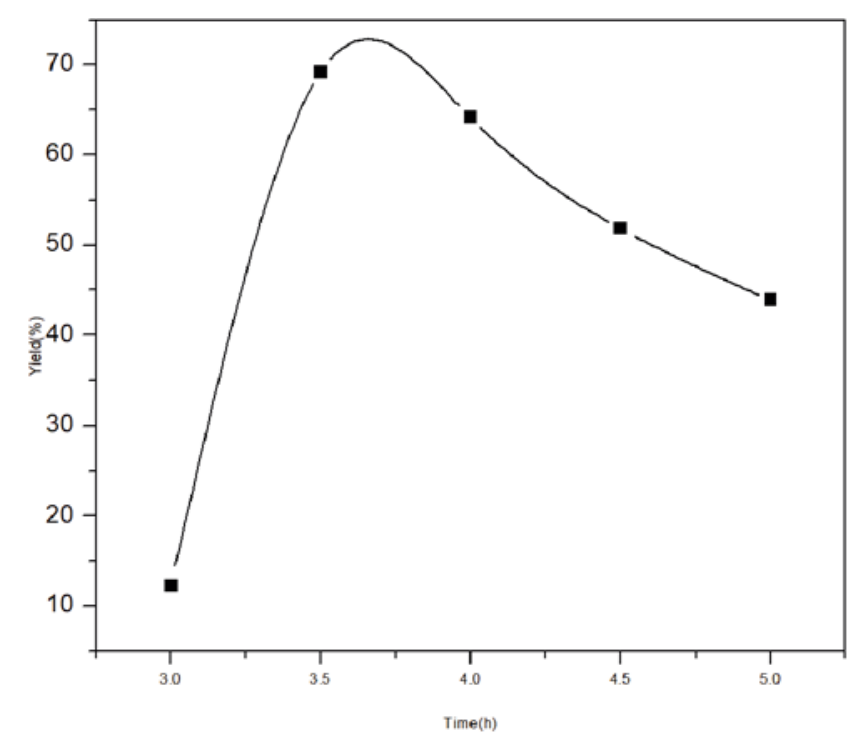

Figure 7. Effect of the reaction time on the yield of thiourea

\section{The reproducibility of the reaction}

The thiourea synthesis was repeated to investigate the reproducibility of the reaction using the optimal reaction conditions (Reaction time $=3.5 \mathrm{~h}$, reaction temperature $=348 \mathrm{~K}$, and mass ratio of urea to Lawesson's reagent $=2: 1$ ). The experimental results are shown in Table 1 .

The results show that under the optimal reaction conditions, the yield was maintained between $58 \%$ and $66 \%$, and the average yield was $62.37 \%$. 
Table 1. Repeated experimental data

\begin{tabular}{|c|c|c|c|c|c|c|}
\hline $\begin{array}{c}\text { Reaction } \\
\text { number }\end{array}$ & $\begin{array}{c}\text { Mass ratio of } \\
\text { Lawesson's reagent } \\
\text { and urea }\end{array}$ & $\begin{array}{c}\text { Temperature } \\
{[\mathrm{K}]}\end{array}$ & $\begin{array}{c}\text { Time } \\
{[\mathrm{h}]}\end{array}$ & Absorbance & $\begin{array}{c}\text { Content } \\
{[\mathrm{mg}]}\end{array}$ & $\begin{array}{c}\text { Yield } \\
{[\%]}\end{array}$ \\
\hline 1 & $2: 1$ & 348 & 3.5 & 3.10087 & 459 & 60.39 \\
\hline 2 & $2: 1$ & 348 & 3.5 & 3.29298 & 486 & 63.95 \\
\hline 3 & $2: 1$ & 348 & 3.5 & 3.39310 & 475 & 62.50 \\
\hline 4 & $2: 1$ & 348 & 3.5 & 3.37200 & 502 & 66.05 \\
\hline 5 & $2: 1$ & 348 & 3.5 & 3.22837 & 448 & 58.94 \\
\hline & & & & & Average yield & 62.37 \\
\hline
\end{tabular}

\section{Structural characterization of the thiourea product}

\section{Infrared spectroscopy}

The as-prepared thiourea sample was investigated using FT-IR spectroscopy in the wavenumber range of $4000-400 \mathrm{~cm}^{-1}$, as shown in Fig. 8.



Figure 8. FT-IR spectrum of thiourea

Characteristic absorption peaks at 3429, 3216, and 1081, $1503 \mathrm{~cm}^{-1}, 1190 \mathrm{~cm}^{-1}$. The peak observed between 3429 and $3216 \mathrm{~cm}^{-1}$ is the characteristic absorption peak of the primary amine, the peak between 1081 and $1190 \mathrm{~cm}^{-1}$ is the characteristic absorption peak of $\mathrm{C}=\mathrm{S}$, and the characteristic peak of $\mathrm{CN}_{3}$ is observed at $1503 \mathrm{~cm}^{-1} \mathbf{1 4 , 1 5}$.

\section{X-ray diffraction}

XRD was used to characterize and compare the asobtained thiourea product and standard sample, respectively. As shown in Fig. 7, the black line represents the XRD pattern recorded for the standard thiourea sample and the blue line represents the as-obtained product. The characteristic diffraction peaks of the standard sample are observed at $20,21,23,26,30,32,35$, and $36^{\circ}$. These diffraction peaks are also present in the XRD pattern of the product obtaining using our synthetic method, which confirms that the as-obtained material is thiourea. There are also some small peaks observed in the XRD pattern of our product that correspond to the impurities formed during the reaction.

\section{Thermogravimetric analysis}

The TGA curves of the standard thiourea sample (black line) and the as-synthesized thiourea product (blue line) are shown in Fig. 8. The TGA curve of the thiourea standard can be divided into three stages, namely in the temperature regions below $175^{\circ} \mathrm{C}$, between $175-250^{\circ} \mathrm{C}$, and above $250^{\circ} \mathrm{C}$. At $<175^{\circ} \mathrm{C}$, thiourea is in its molten state. This region is accompanied by the isomerization of thiourea, which includes the formation of ammonium thiocyanate. When the temperature increases to $175-250^{\circ} \mathrm{C}$, the rate of weight loss of thiourea is at its largest and is accompanied by gas generation, which indicated the decomposition of thiourea. When the temperature is $>250^{\circ} \mathrm{C}$, the reaction is obviously slow, and the isomerized product and the decomposition products were decomposed into guanidine. The TGA

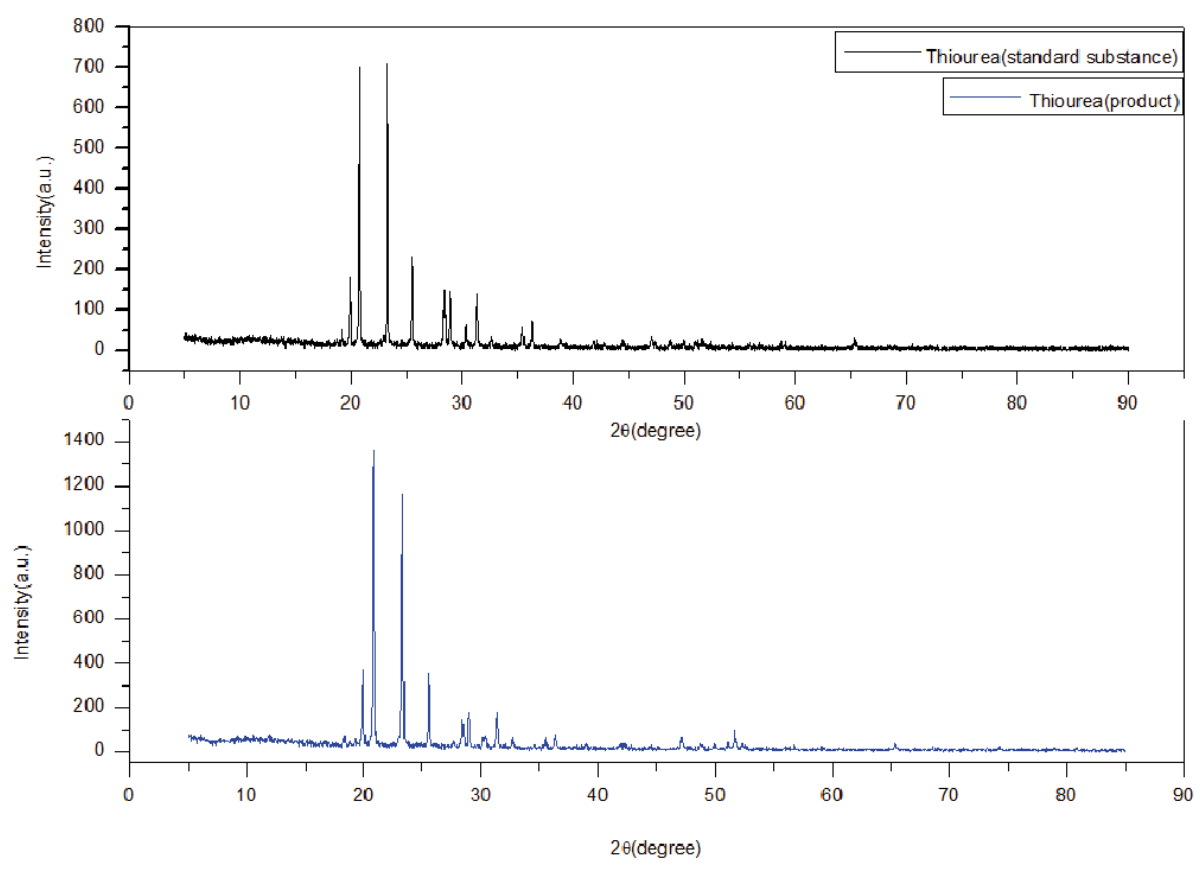

Figure 9. The XRD patterns recorded for a standard sample of thiourea and the as-obtained product 
curve of the as-synthesized product is also divided into three stages, in the temperature regions below $150^{\circ} \mathrm{C}$, between $150-230^{\circ} \mathrm{C}$, and above $230^{\circ} \mathrm{C}$. The two curves have similar trends in the first two stages, and the main component is thiourea. At $>230^{\circ} \mathrm{C}$, the curve is slowly reduced, which can be attributed to the ammonium thiocyanate formed via the isomerization of the Lawesson's reagent by-product and the decomposition of the thiourea product into anthraquinone.

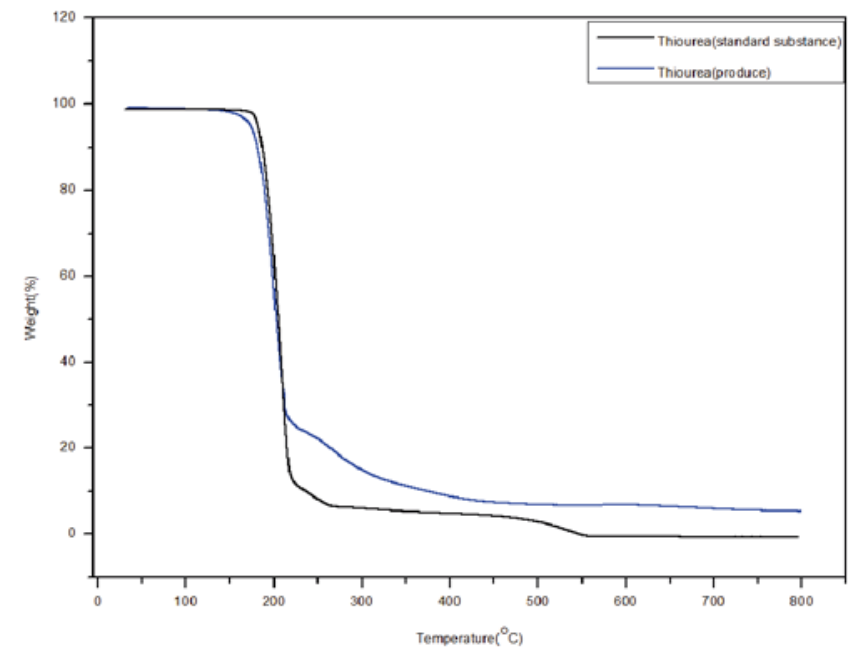

Figure 10. TGA curves recorded for a standard sample of thiourea and the as-obtained product

\section{CONCLUSION}

In this study, urea and Lawesson's reagent were used as raw materials to prepare thiourea by one-step method, and the reaction mechanism was analyzed. The optimal reaction conditions were determined as follows: Reaction time $=3.5 \mathrm{~h}$, reaction temperature $75^{\circ} \mathrm{C}$, and mass ratio of Lawesson's reagent and urea $=2: 1$. The average yield of the repeated experiments was $62.37 \%$. Repeated experiments are carried out under the most beneficial conditions for the preparation of thiourea. The maximum yield of the repeated experiments is $66.05 \%$ and the average yield reaches $62.37 \%$, which is higher than the highest yield of $60 \%$ reported in the current literature. The characterization results of the products obtained using our synthetic route confirm the target product, thiourea was formed. Our process is short, high yielding, and uses mild reaction conditions. The research results lay the foundation for the industrial production of thiourea.

\section{ACKNOWLEDGEMENT}

The authors would like to thank the Jilin Science and Technology Department and Shandong Chambroad Holding Group Co., Ltd. for their support of this research.

\section{LITERATURE CITED}

1. Wang, C., Wang, Z. \& Liang, W., et al. (2016). Catalytic Thiourea Promoted Electrophilic Thiocyanation of Indoles and Aromatic Amines with NCS/NH4SCN[J]. Chinese J. Chem. 34(11):1081-1085.DOI: 10.1002/cjoc.201600344.

2. Vallavoju, N., Selvakumar, S. \& Pemberton, B.C., et al. (2016). Organophotocatalysis: Insights into the Mechanistic Aspects of Thiourea-Mediated Intermolecular [2+ 2] Photocycloadditions[J]. Angewandte Chemie, 128(18), 5536-5541. DOI: 10.1002/anie.201600596.
3. Venkatachalam, T.K., Mao, C. \& Uckun, F.M. (2004). Effect of stereochemistry on the anti-HIV activity of chiral thiourea compounds[J]. Bioorg. \& Medic. Chem. 12(15), 4275-4284. DOI: $10.1016 /$ j.bmc.2004.04.050.

4. Sahu, M.P., Solanki, N.S. \& Dashora, L.N. (2010). Effects of Thiourea, Thiamine and Ascorbic Acid on Growth and Yield of Maize (Zea mays L.)[J]. J. Agron. \& Crop Sci. 171(1):65-69. DOI: 10.1111/j.1439-037X.1993.tb00437.x.

5. Demirbas, A., Pehlivan, E., Gode, F., Altun, T. \& Arslan, G. (2005). Adsorption of $\mathrm{Cu}(\mathrm{II}), \mathrm{Zn}(\mathrm{II}), \mathrm{Ni}(\mathrm{II}), \mathrm{Pb}(\mathrm{II})$, and $\mathrm{Cd}(\mathrm{II})$ from aqueous solution on Amberlite IR-120 synthetic resin. J. Colloid Interface Sci. 282, 20-25. DOI: 10.1016/j. jcis.2004.08.147.

6. Birinci, E., Gülfen, M. \& Aydin, A.O. (2009). Separation and recovery of palladium(II) from base metal ions by melamine-formaldehyde-thiourea (MFT) chelating resin. Hydrometallurgy. 95, 15-21. DOI: 10.1016/j.hydromet.2008.04.002.

7. He, Y., He, L. \& Peng, S. (2013) Industrialization test of thiourea produced by urea-cyanide calcium method. Guang. Chem. Ind. 40(15), 31-32. DOI: 10.3969/j.issn.10071865.2013.15.016.

8. Li, Z. (2005) Study on the new process of preparing thiourea from urea. Tianjin University, TianJin, China. 29-34.

9. Li, Z. (2005) Study on the new process of preparing thiourea from urea. Tianjin University, TianJin, China.7-8.

10. Xu, D. (2012) Preparation and application of substituted thiourea. Nanjing University of Science and Technology, Nanjing.

11. Ji, W. The Researeh for Novel Synthesis of Thiourea and ItS Use, Nanjing University of Technology, Nanjing. 2005, 2

12. Li, Z. (2005) Study on the new process of preparing thiourea from urea. Tianjin University, TianJin, China. 5-6.

13. Xu, Q., et al. Discussion on the Process of Acidic Gas Recovery and Production of Thiourea from Jingbo Petrochemical Refinery[J]. Guangdong Chem. Ind. 2013, 40(4), 45-46.

14. Liu, G., Ma, L. \& Jie, L. (2002). Chemical and chemical properties handbook. Chemical Industry Press.

15.Wei, W. \& Zhongju, D. (1999). Organic chemical materials. Chemical Industry Press. 